Proceedings

\title{
Marine and Terrestrial Scavenging on Fish and Gull Carcasses on a Mediterranean Island ${ }^{\dagger}$
}

\author{
Daniel Redondo-Gómez **, M.-Martina Quaggiotto, David M. Bailey, Sergio Eguía, Zebensui Morales-Reyes, Beat- \\ riz de las Nieves López-Pastor, Daniel Martín-Vega, Carlos Martínez-Carrasco, Esther Sebastián-González, José \\ Antonio Sánchez-Zapata and Marcos Moleón
}

† Presented at the 1st International Electronic Conference on Biological Diversity, Ecology and Evolution, 1531 March 2021; Available online: https://bdee2021.sciforum.net/.

\begin{abstract}
Scavenging is key to understanding ecosystem structure and functioning, both in terrestrial and aquatic environments. Here, we compare the structure and carrion consumption efficiency of the scavenger communities occurring in terrestrial and shallow marine habitats on and around a Mediterranean island. During July 2018, we monitored the consumption of 23 fish (Sparus aurata) and 34 bird (Larus michahellis) carcasses in Grosa Island (Murcia, SE Spain), which were placed both on land and below water. We recorded the vertebrate and invertebrate species occurring at carcass sites by means of visual inspection (vertebrates and invertebrates in marine habitats and invertebrates in terrestrial habitats) and motion-triggered cameras (vertebrates in terrestrial habitats). The vertebrate scavenger community was richer in the marine environment, whereas the total and invertebrate community were richer in the terrestrial one. The scavenger community was usually well-structured (i.e., nested), with the exception of the community associated with fish carcasses on land, which were very efficiently detected and consumed by yellow-legged gulls. In contrast, gulls left conspecific carcasses almost untouched, thus allowing longer persistence of gull carcasses on land and their exploitation by a diverse insect community. Our study shows important differences in the scavenging process associated with both the environment and carcass type.
\end{abstract}

Keywords: carrion; scavenger; environment; marine carcasses; scavenging efficiency; community structure

Citation: Lastname, F.; Lastname, F.; Lastname, F. Title. Proceedings 2021, 68, x. https://doi.org/10.3390/xxxxx

Academic editor:

Published: date

Publisher's Note: MDPI stays neutral with regard to jurisdictional claims in published maps and institutional affiliations.

Copyright: (c) 2021 by the authors. Submitted for possible open access publication under the terms and conditions of the Creative Commons Attribution (CC BY) license (http://creativecommons.org/licenses /by/4.0/). 